\title{
Mass-audience interactive narrative ethical reasoning instruction
}

\author{
Mark Piper ${ }^{1}$ (D)
}

Published online: 23 February 2017

(C) Springer International Publishing AG 2017

\begin{abstract}
In this paper I introduce, elaborate, and defend a new form of ethical reasoning instruction. The pedagogy, which I have titled mass-audience interactive narrative (or MAIN) ethical reasoning instruction, is an initiative designed to teach ethical reasoning effectively on a broad scale over an extended period of time. The hope is that such a program, if duly supported, will help to ensure the widest possible engagement, and high levels of retention, in an institution-level program of ethical reasoning.
\end{abstract}

Keywords Ethics $\cdot$ Instruction $\cdot$ Ethical reasoning $\cdot$ Narrative $\cdot$ Second-person

\section{Introduction and background}

An extensive initiative is underway at my institution that seeks to teach ethical reasoning skills to all of the institution's constituencies. ${ }^{1}$ At the most general level, the initiative is focused upon replacing habits of reflexively judging ethical matters with habits of reflectively judging them with the aid of a system of careful ethical reasoning. ${ }^{2}$ That system of reasoning - and the core of the entire initiative - is found in what are termed the 'Eight Key Questions'. ${ }^{3}$ In just a moment I will say a bit more about the 8KQ project, but before

\footnotetext{
${ }^{1}$ This program has deep connections to the "campuswide process [called] moral conversation" discussed by Nash et al. (2008).

${ }^{2}$ In this respect, the initiative is, among other things, an attempt to push back against the findings of Jonathan Haidt, who has argued that "moral reasoning is usually a post hoc construction, generated after a judgment has been reached" (Haidt 2001, 814).

${ }^{3}$ The $8 \mathrm{KQ}$ initiative, which is known formally at my institution as the Madison Collaborative: Ethical Reasoning in Action, was principally designed by my colleague Bill Hawk. I am grateful to him for his work on this important project.
}

Mark Piper

pipermc@jmu.edu

1 James Madison University, Harrisonburg, VA, USA 
proceeding, it is vital to say a few words in order to clarify the purposes of this paper and properly set reader expectations.

My primary goal in this paper is to argue in favor of a general pedagogical approach to ethical reasoning instruction, not to argue in favor of the $8 \mathrm{KQ}$ model per se, however interesting and important that model may be in its own right. I have incorporated the 8KQ model into this paper for two reasons: first, because I developed the ethical reasoning pedagogy discussed below in the course of working on the $8 \mathrm{KQ}$ project at my institution, and second, because illustration of the ethical reasoning pedagogy I wish to introduce requires particular content, and the $8 \mathrm{KQ}$ approach provides that content as well as any other ethical reasoning system can. Indeed, the ethical reasoning pedagogy I introduce in what follows can be used as a platform or vehicle for instruction in virtually any system of critical reasoning. All that is required is a system of reasoning that can be taught in parts, or stages, over time. It must be clear to the reader, then, that the present paper neither necessitates unpacking the $8 \mathrm{KQ}$ model extensively nor requires justification that the $8 \mathrm{KQ}$ approach is the best approach to ethical reasoning. Personally I think the $8 \mathrm{KQ}$ model is compelling in many ways, but the reader needn't share this view by any means. At bottom, the 8KQ is simply being used as a compelling illustrative example to provide content for the general pedagogical structure that is my real focus. Given this, I will devote very little space to the $8 \mathrm{KQ}$ approach itself. Although I will refer to the 8KQ a good deal in what follows, readers should feel free to substitute this approach to ethical reasoning with a different one if they wish. With this caveat in hand, I can now say a bit more about the 8KQ approach without concern that doing so will prompt otherwise very reasonable and proper calls for further clarification and justification. ${ }^{4}$

The Eight Key Questions ( $8 \mathrm{KQ}$ ) comprise the major traditions of ethical reasoning employed throughout history. As such, the $8 \mathrm{KQ}$ do not contain novelty and do not purport to do so. The 8KQ instead consist of essential concepts which are paired with core ethical question(s) that one can ask when reflecting on how to respond to ethically significant situations. Here is the list:

FAIRNESS: How can I act equitably and balance legitimate interests?

OUTCOMES: What achieves the best short- and long-term outcomes for me and all others?

RESPONSIBILITIES: What duties and/or obligations apply?

CHARACTER: What action best reflects who I am and the person I want to become?

LIBERTY: How does respect for freedom, personal autonomy, or consent apply? EMPATHY: What would I do if I cared deeply about those involved?

AUTHORITY: What do legitimate authorities (e.g. experts, law, my religion/god) expect of me?

RIGHTS: What rights (e.g. innate, legal, social) apply? ${ }^{5}$

\footnotetext{
${ }^{4}$ Readers wishing to learn more about the $8 \mathrm{KQ}$ model are kindly directed to explore the resources and literature available on my home institution's website (https://www.jmu.edu/mc/).

${ }^{5}$ The order of the concepts and associated questions has been determined, not by ethical reasons of any kind, but rather by the desire to create a memorable mnemonic (FORCLEAR).
} 
In virtually all discussions about ethical justification, one or more of these concepts will be present; they are natural ethical 'go-to' considerations that possess a culturally and historically wide base of reference.

The 8KQ are inclusive. Consequentialists, deontologists, virtue ethicists, divine command theorists, rights theorists, care ethicists, and libertarians: all of these and more will find their favored ethical concepts given a place here. This pluralistic approach to ethical reasoning seeks to teach members of the institution to take most or all of these considerations seriously when faced with complicated situations that require careful reflection in order to determine what one ought to do. Of course, not all of the $8 \mathrm{KQ}$ will be equally salient for every ethically significant situation, but many or even most of them will be for most situations. The 8KQ are thus best likened to a tool belt of powerful resources which, usually in combination, provide the resources to thoroughly and responsibly understand or resolve the ethical problems one faces. It should be stressed that the $8 \mathrm{KQ}$ do not comprise an algorithm that allows for the determination of the one and only one action that will satisfy the demands of the various ethical considerations contained therein. Rather, the 8KQ are designed to guide reflection, to provide new avenues for inquiry that may have been overlooked, and to generate a robust sense of the complexity of responsible ethical reflection.

Since the $8 \mathrm{KQ}$-based ethical reasoning project began at my institution, numerous pedagogical initiatives have been designed and implemented, and thus far the results have been heartening. Yet the slate of initiatives, while successful on many fronts, seemed to lack an extended, broad-scale component that would train the majority of students at the institution in the ethical reasoning system in a manner that would facilitate long-term retention. Put another way, it seemed to me that although there were plenty of individual 'bricks' of $8 \mathrm{KQ}$ engagement, there was, for the most part, no unifying 'mortar' to ensure that everyone who matriculated at the university received proper instruction in the framework; and where such 'mortar' could be found, the exposure times were too short to facilitate retention.

In response to this, I developed a form of ethical reasoning instruction that I have since titled mass-audience interactive narrative (or 'MAIN') ethical reasoning instruction. This paper provides an introduction to this form of instruction. In what follows I wish to describe, illustrate, and motivate this pedagogical approach. Near the end of the paper I discuss and respond to possible concerns relating to an ethical reasoning initiative of this kind.

Before proceeding, however, I must state very clearly that although I reference the empirical literature to support certain general features of MAIN ethical reasoning instruction (for example, its use of narrative, and its student-centered approach, among others), this paper does not contain extensive empirical defense of this form of ethical reasoning instruction in action over time. As this is a new idea which has not yet been adopted for a considerable length of time, I do not have, and do not claim to have, the benefit of being able to reference an extensive range of assessment data as evidence for the efficacy of this model. ${ }^{6}$

\footnotetext{
${ }^{6}$ This is not to say that no data is available, only that the data is not extensive. Discussion and analysis of available data can be found in Ames et al. (2016), 'Impact and persistence of ethical reasoning education on student learning: results from a module-based ethical reasoning educational program' (also published by the International Journal of Ethics Education). The 'module-based ethical reasoning educational program' discussed in that article is, in fact, the very ethical reasoning instruction model that I developed and which I introduce and defend in the present article.
} 
Yet I think a case can be made for the model prior to widespread implementation. My goal is not to show that this approach has worked; rather it is to present and motivate this approach to ethical reasoning instruction as a proposal that deserves further consideration and possibly further adoption. In short, I seek to make a case for the merits of a new pedagogical model as worthy of being employed.

\section{MAIN ethical reasoning instruction: general structure}

At the heart of this program of ethical instruction is a story told in the second person. The place and importance of narration, and specifically second-personal narration, cannot be overemphasized. Second-personal narration avoids a key problem that third-person and even first- person narratives share: the problem of distance. Simply put, third- and first-personal narration is centered on foreign characters (unless, in the first-personal case, one is reading one's own autobiography). Coming to sympathize with such characters can require a considerable amount of effort on the reader's part. By contrast, second-personal narration throws the reader immediately into the story as a character taking part in the tale. Instead of reading at a distance ("Joe woke up, having overslept his alarm"), the reader becomes a person within the story itself ("You wake suddenly and find that you have overslept your alarm"). Second-personal narration lends itself to quick engagement and heightened personal investment over time. By projection, that character becomes you.

But how long should the story be, and how should it be structured? The demands of retention suggest that the exposure should be extended and reiterated. Developing a habit of employing the $8 \mathrm{KQ}$ skillfully is not a goal that can be achieved quickly. With this in mind, I decided on a multiple-episode format comprising 8 episodes, all of which would be unified as parts of a 'season,' in much the same way that many television series are structured. The season as a whole would require an overarching thematic unity, and all of the episodes would have to be written in such a way that they would have their own episode-level unity, and would cohere with one another while standing as interesting episodes (with plot twists, new characters, and the like) on their own. After reflecting and consulting with others working on the broader ethical reasoning program at my institution, it was judged that one week between episodes would allow for the right pacing between too rapid and too plodding.

But how would the ethical content be conveyed, and where would it be found in the stories? The end of each episode seemed the most appropriate. At the end of each episode you (the reader) would face an ethically significant situation that required choosing between various actionable possibilities. You would then be asked to choose between the available options and, crucially, to justify your choice using the 8KQ. This would become the standard structure of all of the episodes. In each episode, then, participants would be presented with a second-personal account of a character engaging in various activities, culminating in an ethical problem requiring choice and justification; and, every time, the resources for providing that justification would be given by the $8 \mathrm{KQ}$. In this way, participants would, over the course of several weeks, gain considerable experience employing the 8KQ for purposes of ethical justification. The underlying hope behind such a decision was that 
repeated practice using the $8 \mathrm{KQ}$ would be an effective way to turn $8 \mathrm{KQ}$ usage into less of an isolated task and more of a habit, and would facilitate 8KQ skill development. ${ }^{7}$

Although this seemed a good start, it occurred to me that engagement would be heightened if the participants could, to some extent, determine the progression of the story. This could be accomplished if, every time a cohort of participants judged on an ethical matter at the end of an episode, the votes were tallied and whichever option received the largest number of votes would impact, to some extent, what happens in the subsequent episode. If, presented with a choice between action $\mathrm{A}$ or action $\mathrm{B}$, the majority were to vote in favor of action A, then the next episode would be modified, even if only slightly, to accommodate this by showing the character doing A. The cohort of participants wouldn't know what impact their votes had upon the next story until it was released, at which point the participants would be able to see how they voted, after which they would read the new episode, complete with the character following the route favored by the majority. In this way, participant voting would have an impact upon the unfolding of the story itself, and the participants would be aware of this.

I incorporated the participant-receptivity model, in part, to take advantage of the prevailing interest in reality television and interactive social media. The hope is that, if successful, these practices will lead to greater exposure for the story itself, which will ideally generate greater discussion and usage (spontaneous or planned) of the 8KQ as members of the institution converse about the story and what ethical choices ought to be (or have been) made. Making participant feedback impactful in this way could greatly aid in creating a general atmosphere of interest in which the participants would want to share their take on the story and justify their judgments. With the proper social and technological support, this does not seem unrealistic.

As some readers may have noticed, this approach to ethical reasoning instruction is not dissimilar to what one finds in the Pick-a-Path or Choose Your Own Adventure book series. There are important differences as well, of course. These include (a) the realism of the action in the ethical instruction stories, (b) the fact that the final decision of the episode must always be ethical in nature, (c) the fact that completing the 8episode season of narrative ethical reasoning instruction would involve a significant time commitment, (d) the elements of ethical pedagogy contained in the ethical narratives, and (e) the communal nature of the story determination.

One topic that deserves further comment is how best to structure the resolution of each episode. ${ }^{8}$ Assuming that the students have read the episode, have been faced with an ethical choice, have chosen and have justified their choice, and have collectively determined how the ethical challenge is to be met, what happens next? Certainly the story will continue, but it is also reasonable to expect that the resolution of an episode - the final, collective judgment about the best way ethically to proceed — will have, or be given, pedagogical significance. But what might this look like?

The answer to this question will depend crucially on both the form of ethical reasoning being taught and the precise learning objectives laid down by the persons

\footnotetext{
${ }^{7}$ It deserves repeating that this general structure can be employed in the service of teaching just about any form of ethical reasoning, not just the $8 \mathrm{KQ}$ model. Consequentialist, deontological, virtue ethical, care ethical, and contractualist approaches to ethical reasoning, and many more besides, can all be taught using this method.

${ }^{8}$ I would like to thank an anonymous reviewer for the International Journal of Ethics Education for pressing me on this point.
} 
directing the project. In the case of the $8 \mathrm{KQ}$ model, which is highly pluralistic and geared far more towards stimulating a broad and inclusive form of ethical reflection than towards generating consensus in ethical judgment, I suggested that the resolution could be accompanied by examples of excellent student justifications of different ethical judgments (in response to the ethical choice faced), along with expert commentary on the ethical choice in relation to the Key Questions. The idea was to help students appreciate the complexity of the ethically significant situations we often face in life, not to show them the correct answer. However, a resolution of this kind well may be out of place in other usages of the MAIN method. If one is using MAIN ethical reasoning to teach Bentham's hedonic calculus, for example, the resolution could consist in an instructive moment of a very different kind: say, to show students how the proper employment of Bentham's method results in making a particular ethical judgment (the correct answer) as opposed to others. By contrast, if one is using the MAIN ethical instruction method to teach the ethics of care, a more appropriate resolution might involve elucidating how the different choices one could make in response to an ethically significant situation evince attitudes of care for different people, thereby showing how people can tend to be selective about whom they think worthy of care. Still different ethical reasoning systems and learning objectives will lead those employing the MAIN method to craft different kinds of resolutions, potentially involving different forms of communication at different times. In general, then, the question of how best to resolve episodes is, in my view, best seen as dependent on a variety of related factors of the kind I have elaborated above, and thus should not be determined antecedently without reference to those factors. In this respect, episode resolution should share in the creative unfolding of the story itself.

\section{MAIN ethical reasoning instruction: particular content}

With the general structure of the initiative in place, the next task was to give content to the season as a whole and to the individual episodes: to create a plausible and compelling storyline to unify the whole and its parts, not forgetting interesting characters, unexpected challenges, plot twists, and one concluding ethical challenge per episode. For the general theme and setting of the season, I decided upon the first day of work after graduation (the season itself was titled 'Commencement'). The hope was that this topic would be close enough to students (the primary participant group at our institution) to excite their interest, yet distant enough to force them away from knee-jerk, intuitive forms of ethical judgment. ${ }^{9}$ I also hoped that the topic, which speaks to post-collegiate responsibilities, would be welcomed for that reason by faculty, administration, and parents.

Crucially, the character in the story, and all supporting details about the character, would have to be as neutral as possible, not only in relation to gender, but also in relation to (1) the kind of job held, (2) political, religious, or other ideological convictions, and (3) the circumstances of the character's post-graduation life. The challenge was to make the character and everything about the character's circumstances as underdetermined as possible so that readers could project their personality and life circumstances into the character in order to further the process of engagement through personal appropriation.

\footnotetext{
${ }^{9}$ In this way I hoped to satisfy demands of participant relevance. (See Highet 1950, pp. 49-50.)
} 
Also very importantly, in addition to incorporating material relevant to being able to make a (relatively) informed ethical decision at the end of each episode, the writing would have to be interesting enough as a story in its own right to sustain the reader's attention. In order to give the participants as dynamic and compelling an experience as possible, the story could not be a flat, contrived support structure for an artificial series of ethical problems. Of course, this could not be taken too far; a balance had to be maintained between realism (to reinforce the point that these sorts of ethical challenges are to be encountered in real life) and moderate sensationalism (to maintain reader interest).

For ease of setup and reduced production costs, I decided that it would be best if each episode were written rather than filmed. This was especially important if there was to be an attempt to capture participants' responses in such a way as to modify at least part of the subsequent episode in accordance with participant voting. (Written modifications are cheap and easy; filmed modifications on the fly are not!)

Unsurprisingly, it was clear early on that such an initiative would have to be online. After extensive consultation with the IT experts at our institution, it was decided that the center and repository for the stories and all of the supporting instructions and supplementary information would be a WordPress site. In initial experimentation, the site has proven easy to read and modify. (Of course it is entirely possible that other websites may do a still better job in one way or another.)

Putting all the pieces together, it seemed to me that the nature and purpose of this pedagogical approach was best captured by calling it Mass-Audience Interactive Narrative (MAIN) ethical reasoning instruction.

\section{An illustrative example}

In order to illustrate MAIN ethical reasoning instruction, it might be helpful to share an excerpt of the first episode of my 'Commencement' series. Everything you read below would be read by the participants taking part in this ethical reasoning initiative. The writing would be found on a WordPress site which all can access (but in which only those participants taking part in the exercise possess the power to vote). It is important to remember that this is the first episode of a series of 8 episodes that are all thematically unified and which are to be rolled out over the course of 8 weeks; it is not to be understood as a one-shot narrative intervention.

(Excerpt from Episode 1: "First Things First")

Alarm going off-but you've been up for a couple of hours at least. No chance of sleeping in today-your first day of work.

You took special care when choosing your outfit for the day. You spend more time than usual getting your hair just right. You pour a cup of coffee while going through the emails from the company, wanting to be certain that you haven't overlooked anything that pertains to the day. All looks well. Still good on time. You dress, admire your reflection, and take another sip of coffee. All is well.

Until your iPhone rings off an incoming text message, and your pent-up nerves run away from your control, making you shudder and causing you to spill a good half of your coffee into your lap. 
Damn! There is no quick-fix; you'll have to change. Now the nerves have full play as you rip through your wardrobe, trying to find a proper substitute. No, no, no-no-maybe-ok, yes, that works, but what with it? No, no-maybe? No. Damn. You glance at the clock and see that you are still fine on time. You exhale and return to your wardrobe and decide. Fine, fine-that will do, that's fine. You dress again. Not what you wanted, but it will do. You close your eyes and take a deep breath. No need to panic, all is well. If I leave now, I'll be on time.

You begin to gather your things, and as you do so you remember the text-you never checked it. It's from Mom: Your father and I are proud of you! Don't forget that you agreed to visit your grandfather in the hospital this morning before heading to work. I couldn't help telling him you were coming, sorry! :-) He knows that you don't have much time, but you know your grandfather-he'll be telling everyone by now that you're coming. Just make it quick and he'll be happy. Love you!

Unbelievable. Simply unbelievable. This is what you had forgotten. Somehow you thought it was next week. You double-check your calendar and it stares you in the face: "Monday-short surprise visit to Gramps."

You have to get to work on time - it's your first day of work! But the coffee-drama has cut away at your time. If you leave now, you can visit your grandfather in the hospital, but then you will be late for work. Or you can make it to work on time, but then you can't visit your grandfather. You could send a message explaining why you couldn't come to the hospital, but you know your grandfather will be greatly disappointed, and, given your schedule, it is highly unlikely that you'll have a chance to visit him later during the day.

You have two options: either you can (1) visit your grandfather in the hospital, and arrive to work late, or (2) arrive to work on time, and stand up your grandfather, who is expecting and has likely already told others of your 'surprise' visit this morning. Of course you can call the hospital and let your grandfather know the reason for not arriving, but you know that this will not diminish his sense of disappointment, and chances are that you won't be able to visit him at any point later in the day. You must make a decision.

Remember, you are being asked to judge what is the ethically right thing to do, not necessarily what is in your personal interests.

Which option do you choose?

After you have made your decision, make sure to justify your decision in relation to the Key Question in play in this episode.

\section{Advantages of MAIN ethical reasoning instruction}

MAIN ethical reasoning education contains many advantages. Some of them have already been mentioned above: the inclusion of participant-receptive voting, the ease of participant interface with the hosting site and the concomitant ease of voting and discovering wider voting trends, and the merits of basing a narrative project of this kind upon a second-personal form of narration that has excellent chances of engaging participants quickly and making them feel a sense of investment in the character and the character's story. 
Empirical data can be referenced to support the effectiveness of the pedagogy that defines MAIN ethical reasoning instruction. A considerable amount of research suggests that humans are especially disposed to remember, enjoy, and learn from stories and narratives (Witherwell and Noddings 1991; Nuthall and Alton-Lee 1995; Witherell 1995; McEwan and Egan 1995; Nuthall 1999; Heath and Heath 2007). In addition, there are several reasons to think that this form of instruction scores well in terms of participation motivation. For example, the public, shared, participant-receptive nature of the experience promotes a form of cooperative learning: participants not only engage in the project, but they do so in the knowledge that others are doing so as well. Without the pressure of trying to find the one right answer, participants and others involved will see themselves as working together to find the best solutions to common problems. This kind of cooperation is socially reinforcing, and research suggests that this improves participant motivation (Ames 1981; Slavin 1984). Also, the likelihood of high public interaction relating to the narrative will likely increase participants' attention levels (Kerman 1979; Wlodkowski 1999). Moreover, the novelty of this widely shared, extended form of ethical reasoning instruction - which is not intended for traditional grading-lends itself to participants becoming less focused on assessment, which allows for intrinsic motivation to develop (Covington and Wiedenhaupt 1997). Furthermore, the kind of engagement at work in this form of ethical reasoning instruction puts more power in participants' hands: they determine how their character chooses; they determine the key ethical factors that are most salient for the ethical problem at hand; they collectively determine how the story progresses. This kind of empowerment has been linked with increased motivation, confidence, and enthusiasm for learning (Deci and Ryan 1987; Weimer 2002).

A practical advantage of this form of ethical reasoning instruction is to be found in the fact that it is indefinitely reusable. All that is required is to change the story while keeping the preexisting structure in place. I would go so far as to say that it is a necessity - a happy necessity, but a necessity nonetheless - for those seeking to continue to employ this form of ethical reasoning instruction into the future. It goes without saying that different stories - with different plots, characters, settings, and developments - will provide a backdrop against which to develop a variety of different ethical challenges, and changing the story will keep the participant pool curious and expectant (what will the new story be?).

In addition, and as mentioned above, MAIN ethical reasoning instruction is entirely compatible with ethical reasoning programs or principles that do not match or rely on the $8 \mathrm{KQ}$. All that is required is an ethical system of some kind that can be divided up into component parts and taught in the iterated narrative way characteristic of MAIN ethical reasoning instruction discussed above.

As a final comment, I might mention that it is that it is always possible, and perhaps pedagogically desirable, to have a final episode or installment that is devoted to getting the participants to take a meta-perspective on the entire process once the series is over. Such a process could greatly accelerate the participants' internalization of the core lessons of the initiative and, ideally, make it more likely for students to use this method of ethical reasoning outside of the institution. It could also be an opportunity for giving special honor to those participants who, from their posts, engaged in ethical deliberation with the most care, earnestness, consistency, and wisdom. 


\section{Possible concerns}

Here I wish to focus on three possible concerns about MAIN ethical reasoning instruction. The concerns relate to (i) the workload required to run the program, (ii) the quality of participant involvement, and (iii) ensuring participation.

\section{Concerns about the workload}

One concern surrounding MAIN ethical reasoning instruction might be that it is too labor intensive. Getting this kind of program off the ground requires story writers, website organization and maintenance, and advertising support. And once the initiative is underway, incorporating the results of participant voting will require modifying or tweaking aspects of future episodes to reflect that voting. This all requires a good deal of time-perhaps too much time.

I do not deny that there is a good deal of work involved. But the work is largely at the front end, and some of the front end work is fairly easy for those with the relevant experience. For example, creating the website can be a quick affair for IT professionals, especially if the site is streamlined and content-light. Gathering participant votes for each episode can be facilitated through the use of an online survey system such as Qualtrics, which is easy to set up. And although it is true that satisfying the participant response aspect of the program requires tweaking future episodes to match voting, it is not necessary to change the entire plotline or rewrite entire episodes. It is only necessary to set up ethical questions at the end of episodes where the responses from which participants can choose would affect the story somewhat, but would not impact the core unfolding of the narrative. Tweaking a subsequent episode after a round of voting would, in most cases, involve little more than making adjustments to the first couple of paragraphs.

The greatest amount of labor will be creating the overarching theme and plot of the season of episodes, and especially writing the episodes themselves. Here there are no quick fixes; a devoted writer or group of writers will have to commit a good deal of effort over a decent stretch of time. In my case, I wrote the eight episodes for 'Commencement' over the course of a summer. My work was supported by a curriculum development grant, and perhaps a similar incentive at other institutions could overcome any hesitations regarding the time investment required. As a final consideration, I might add that the potential returns on the time investment are considerable. The vision of an institution united in discussion about the ethical issues surrounding an ongoing story - justifying viewpoints, rethinking what has ethical relevance, waiting to see how the story develops, attempting to convince others to vote in particular ways because it best accords with ethical standards - is very compelling.

\section{Concerns about the quality of participant involvement}

Another concern is that the very size of the initiative will make it difficult, if not impossible, to supervise the quality of participant involvement. Realizing this, some participants may invest very little in the initiative. Their involvement may constitute little more than skimming through the episodes, making ethical decisions without reflection, and writing justifications that are little more than meandering, off-the-cuff blather. 
This is a legitimate concern, but three responses can be given. First, although some participants will loaf, cut corners, or shrug off the opportunity for learning, this is the case for almost any large-scale initiative, and hence shouldn't be considered a special reason for doubting this initiative in particular. Second, and more to the point, there is good reason to think that the likely benefits will outweigh the negatives. Properly advertised and supported, an initiative of this kind can become a powerful event that unites students, faculty, administration, and even staff in an engaging and entertaining yet instructive enterprise. And third, it is always possible to offer incentives to participants to engage in the initiative in a more careful manner. Ideally such incentives could be offered at the class level by participating faculty, as this would allow for more careful attention to participant responses. For example, professors could offer extra credit to the students in class who had the most impressive justification writings in support of their ethical decisions. But many other kinds of incentives could be offered.

\section{Concerns about how to ensure participation}

A final concern relates to the question of how to ensure participation. This is largely a logistical question, but there are complications that go beyond logistics. The two main approaches that can be taken to ensuring (or motivating) participation are (a) offering benefits to voluntary participants or (b) forcing participation by establishing penalties for noncompliance-in short, the carrot or the stick. Positive incentives for voluntary student participation, for example, could include extra credit in particular classes, resume-enhancing badges in ethical reasoning, inclusion in a lottery drawing (for money, new technology, etc.) upon completion of the program, or registration queue advantages. Penalties for nonparticipation could include registration holds, GPA penalties, or the suspension of certain privileges.

What is the better way to ensure participation: the carrot or the stick? Arguments can be made on both sides. On the one hand, offering positive incentives rather than the threat of punishment for nonparticipation will be more likely to result in a satisfied participating body. The downside is that such an approach will almost certainly fail to attract wide participation, as some will not be enticed by whatever incentives are on offer. By contrast, establishing penalties for nonparticipation will ensure the widest possible participation, but may cause dissatisfaction, resistance, and low effort amongst participating students. And there is a further concern about using the stick. This is, after all an ethics initiative: it is focused on teaching ethical reasoning skills against the background assumption that this is important for character development. Ethics takes character seriously. There is something ironic or misplaced about forcing participants to develop character by means of threats.

I doubt that there is one and only one correct response to the question of the best method by which to gain student participation. Different institutions will likely have different profiles that speak in favor of one approach or the other. At some institutions - e.g. small liberal arts colleges with strong preexisting ethical traditions-positive incentives may be very effective in attracting strong participation. At other institutions, penalty processes may be so easily adapted to the program and so widely accepted by students that negative incentives are more appropriate. There will also be cases in which it is unclear which form of participation is best. 
My opinion on the matter is that, all else being equal, it is better to have broader participation, even if this means establishing penalties for non-participation. There is precedent for this. Most pertinently, colleges and universities typically compel students to accept an honor code. Enforcing the code is as much about a commitment to ethical character as it is about avoiding academic deception, yet few seem to think that the commitment to an honor code should be a voluntary matter. By analogy, it is not unreasonable to consider a commitment to ethics education to be so important that the development of ethical reasoning skills is established (and enforced) as a necessary part of a curriculum.

Another argument in favor of compelling participation is that MAIN ethical reasoning instruction has been designed to be a highly engaging and entertaining pedagogical experience. Many students who initially grumble about being forced to read and respond to the episodes will likely find themselves enjoying them, discussing the issues raised within them with their friends and families, and looking forward to finding out how the story progresses and eventually ends. Much the same happens in many classes: students who originally find class demands burdensome come to take enjoyment in the work. MAIN ethical reasoning instruction was designed to capture students' imagination and diminish resistance to the rather minimal labor requirements.

\section{Final comments}

In this paper I have introduced, elaborated, and defended mass-audience interactive narrative (MAIN) ethical reasoning instruction as an initiative designed to teach ethical reasoning effectively on a broad scale over an extended period of time. The hope is that such a program, if duly supported, will help to ensure the widest possible engagement, and high levels of retention, in an institution-level program of ethical reasoning. Perhaps the most important key for this approach is a compelling, accessible story that strikes a balance between realism and sensationalism while making narrative space for the widest possible range of student identification with the story's protagonist. Strong advertising and technological support are crucial as well, as these will facilitate and enable widening circles of institutional engagement. The effort required to establish such a program is certainly not to be overlooked, but the possible fruits of an initiative of this kind are, I would contend, more than compelling enough to warrant the investment.

Acknowledgements I would like to thank Bill Hawk for his work formulating the 8 Key Questions approach and establishing the Madison Collaborative. I would like to thank the QEP Task Force (and especially Dr. Lee Sternberger, the Chair of that Task Force) and the James Madison University College of Arts and Letters (and especially Dr. David Jeffrey, the Dean of the College) for their generous financial assistance in support of the development of the pedagogical model discussed in this paper. I would also like to thank Erin Phillippi for her superb editing work on the first draft of the episodes. I am indebted to the James Madison University Center for Faculty Innovation for kindly allowing me to use their library while doing pedagogical research for this article. Lastly, my sincere thanks to the Madison Collaborative staff and associated faculty and fellows (including Allison Ames, Kristen Smith, Tim Ball, and Lori Pyle) who took part in or provided assistance for the pilot program for this initiative, collected assessment data, supported the writing of this article, and furthered study of the initiative discussed herein with their own excellent research (see Ames et al. 2016). 


\section{References}

Ames, C. 1981. Competitive versus cooperative reward structures: The influence of individual and group performance factors on achievement attributions and affect. American Educational Research Journal 18: 273-388.

Ames, A., K.L. Smith, E.R.H. Sanchez, L. Pyle, T. Ball, and W.J. Hawk. 2016. Impact and persistence of ethical reasoning education on student learning: results from a module-based ethical reasoning educational program. International Journal of Ethics Education forthcoming.

Covington, M.V., and S. Wiedenhaupt. 1997. Turning work into play: The nature and nurturing of intrinsic task engagement. In Effective teaching in higher education: Research and practice, ed. R.P. Perry and J.C. Smart, 101-114. Bronx: Agathon Press.

Deci, E., and R. Ryan. 1987. Intrinsic motivation and self-determination in human behavior. New York: Plenum.

Haidt, J. 2001. The emotional dog and its rational tail: A social intuitionist approach to moral judgment. Psychological Review 108: 814-834.

Heath, C., and D. Heath. 2007. Made to stick: Why some ideas survive and others die. New York: Random House.

Highet, Gilbert. 1950. The art of teaching. New York: Vintage Books.

Kerman, S. 1979. Teacher expectation and student achievement. Phi Delta Kappan 60: 716-718.

McEwan, H., and K. Egan (eds.). 1995. Narrative in teaching, learning, and research. New York: Teachers College Press.

Nash, R.J., D.M. Bradley, and A.W. Chickering. 2008. How to talk about hot topics on campus: From polarization to moral conversation. San Francisco: Jossey-Bass.

Nuthall, G. 1999. The way students learn: Acquiring knowledge from an integrated science and social studies unit. The Elementary School Journal 99: 303-341.

Nuthall, G., and A. Alton-Lee. 1995. Assessing classroom learning: How students use their knowledge and experience to answer classroom achievement test questions in science and social studies. American Educational Research Journal 32: 185-223.

Slavin, R.E. 1984. Students motivating students to excel: Cooperative incentives, cooperative tasks, and student achievement. The Elementary School Journal 85: 53-64.

Weimer, M. 2002. Learner-centered teaching: Five key changes to practice. San Francisco: Jossey-Bass.

Witherell, C.S. 1995. Narrative landscapes and the moral imagination: Taking the story to heart. In Narrative in teaching, learning, and research, ed. H. McEwan and K. Egan, 39-49. New York: Teachers College Press.

Witherwell, C., and N. Noddings. 1991. Stories lives tell: Narrative and dialogue in education. New York: Teachers College Press.

Wlodkowski, R. 1999. Enhancing adult motivation to learn: A comprehensive guide for teaching all adults. San Francisco: Jossey-Bass. 